\title{
Consumer Inertia, the New Economy and EU Competition Law
}

\author{
Vladimir Bastidas Venegas ${ }^{\star *}$
}

ABSTRACT: Services and goods in the new economy, such as social media platforms and applications, are often offered to end-consumers for "free". This may cause problems for the application of traditional antitrust doctrines, such as tying or other forms of leveraging, which normally have been applied to products and services offered at a price. As illustrated by the Microsoft I decision (Windows Media Player), it is not self-evident that the bundling of an application with an operating system results in coercion, the pressure to consume the "tied" product, if consumers have a de facto possibility to download competing products for free. Moreover, the availability of competing products for free may also affect the long-term effects in the market, as both the existing customer base and new customers may easily shift their consumption, which decreases potential "lock-in" effects. This propensity and capability of customers to choose products or services other than the predefined "default" option, e.g. by being included in a bundle, was also relevant in the recent Google decision (Shopping), which concerned the company's preferential placement of its own advertising messages in internet searches. In both Microsoft I and the Google decision, it was found that consumers were unable to choose products and services other than the default option, so-called consumer inertia. Consumer inertia has been explained both by the traditional law and economics literature and behavioural economics with switching costs, information costs and the status quo bias. Accordingly, this article explores the concept of consumer inertia in the light of the law and economics literature, in particular behavioural economics, to determine the factors which are relevant for establishing the presence of consumer inertia in individual antitrust cases concerning the new economy. Moreover, the article evaluates to what extent the use of consumer inertia in cases from the Union courts and the Commission is consistent with economic theory.

\footnotetext{
* Date of Reception: 22 January 2018. Date of Acceptance: 30 January 2018.

** Associate Professor, Uppsala University, 75236 Uppsala, Sweden, vladimir.bastidas@jur.uu.se.
} 
KEYWORDS: consumer inertia, behavioural economics, new economy, tying

\section{Introduction}

The behaviour of consumers is crucial for the economic models that antitrust relies on. Without knowing the consumer's reaction to price increases, marketing, sales methods and contracts, it is impossible to assess the current and future effects of measures taken by firms and ultimately their effect on competition. While a well-informed consumer that makes well-thought and intelligent decisions may engage in the search for better alternatives and thereby "punish" the attempt of firms to impose negative policies, a less informed consumer may accept such measures, which implies a certain degree of market power in the hands of their supplier. Obviously, the difference between well-informed and less wellinformed consumers may have an impact on the measures taken by firms and their effect on competition. While traditional economic theory has assumed a certain degree of consumer awareness, a degree of activity in the searching of alternatives and the calculation of costs and benefits, as well as a certain degree of objectivity in the balancing between different alternatives when making choices that maximise their utility, satisfaction or needs, current trends in economic theory have a different view on consumers' choices. Consumers may be uninformed, lazy, inconsistent and non-objective in their decision-making. This, in theory, gives more leeway for firms to introduce policies which have a negative impact on consumers and competition by other firms. An example of these features that makes consumers less rational than assumed in traditional economic theory is so-called consumer inertia. Recent antitrust enforcement shows that the Commission is aware of consumers' inability to make fully rational and informed choices because of so-called consumer inertia. Accordingly, this article explores the concept of consumer inertia in economic theory and analyses competition law cases where such inertia is arguably present.

\section{What is consumer inertia?}

Somewhat simplified, with consumer inertia, or the status quo bias, it is meant that human beings stay passive instead of making an active choice, or refrain from taking an action that changes the status quo that would 
be economically rational to do. ${ }^{1}$ Typical examples from real-life markets are consumers that do not switch from their bank or electricity company even when States have adopted legal rules actively promoting such switching. Obviously, the concept of consumer inertia is related to the general assumption in economic theory that individuals act in a rational manner. Consumer inertia or the status quo bias is mainly attributed to behavioural economics. ${ }^{2}$ However, consumer inertia has also, and may also be explained by more "traditional" branches of economic theory. This subsection will therefore discuss how consumer inertia may be construed according to economic theory.

It is generally assumed that traditional branches of economic theories like the early Chicago School make a strong assumption of individuals' rationality. ${ }^{3}$ Thus, in such models, an individual (natural or legal person) would acquire an optimal amount of information and engage in balancing the "pros and cons" in the processing of available information when maximising utility. Exactly how strong such an assumption is could be debated. Different models may express different views on the degree of the individual's rationality as well as access to information. Certain branches of economic theory, such as Transactional Cost Economics (TCE), have obviously relaxed the degree of rationality expressed by individuals as well as the amount of information available. ${ }^{5}$ It is not uncommon that uncertainty (about e.g. possible future events) is taken in as a factor or that a distinction is made between short-term and long-term incentives. Accordingly, the exact degree of rationality assumed in economic reasoning may greatly differ among different schools of economics, different scholars, as well as specific models. A minimum common element, perhaps, is the assumption that a (rational) individual would take the available information (e.g. current and past experience as well as information that

\footnotetext{
${ }^{1}$ Beata Mäihäniemi, "The role of innovation in the analysis of abuse of dominance in digital markets: The analysis of chosen practices of Google Search", Market and Competition Law Review 1 (2017): 118.

${ }^{2}$ Christopher Decker, "Concepts of the consumer in competition, regulatory and consumer protection policies", Journal of Competition Law \& Economics 13 (2017): 151-184.

${ }^{3}$ Maurice E. Stucke, "Behavioral antitrust and monopolization", Journal of Competition Law and Economics 8 (2012): 545.

${ }^{4}$ Decker, "Concepts of the consumer", 155.

${ }^{5}$ Oliver Williamson, The Economic Institutions of Capitalism (New York: The Free Press, 1985), 45-46; Oliver Williamson, Markets and Hierarchies: Analysis and Antitrust Implications (New York: The Free Press, 1975), 21-23.
} 
may be acquired) into consideration and engage in a somewhat complex cost-benefit analysis in order to maximise utility. Importantly, what would "impact" the individual in such a context that could lead to an "irrational" decision are factors that are normally characterised as different types of costs, e.g. costs of acquiring sufficient information (information costs) to make a rational decision. ${ }^{6}$

As regards consumer inertia, it would constitute one of those factors under traditional economic theories that constitutes or that results in socalled switching costs. It has e.g. long been recognised that products and services may be differentiated, which makes consumers non-price sensitive as price cuts would not necessarily result in switching between suppliers. This price insensitivity, or brand loyalty, is also a form of consumer inertia that can either be seen as a form of switching cost (from brand switching) and/or a factor that increases costs for rivals and new entrants to compete for a particular (incumbent) supplier's installed base. ${ }^{7}$ The main point is that customers forming part of the installed base may seem to behave irrationally if one would only measure the utility of the supplier's goods or services in terms of objective factors such as price and quality. Moreover, it has also been acknowledged under traditional economic theory that consumers, under special circumstances, may not make well-informed choices, e.g. between competing systems, resulting in consumers being "locked-in" and opening up for exploitation through e.g. higher prices in aftermarkets. ${ }^{8}$ Also, in this example, the consumer does not make a fully rational choice and such irrational behaviour is explained by the fact that the well-informed and rational consumer did not have access to transparent information or that the economic incentives to seek information were not high enough (as information costs were too high) to engage in a fullscale cost-benefit analysis. While the aftermarkets example does not constitute an example of consumer inertia, it demonstrates that traditional economic theory also considers "rationality" problems in terms of information costs because of non-transparent information and lack of information, as well as switching costs.

\footnotetext{
${ }^{6}$ See e.g. Steven Salop and Joseph Stiglitz, "Bargains and rip-offs: A model of monopolistically competitive price dispersion”, The Review of Economic Studies 44, no. 3 (1977): 493.

${ }^{7}$ For the view that brand loyalty is an expression of perceived switching costs by the consumer, see Paul Klemperer, "Competition when consumers have switching costs: An overview with applications to industrial organization, macroeconomics and international trade", Review of Economic Studies 62 (1995): 518.

${ }^{8}$ Carl Shapiro, "Making sense of Kodak", Antitrust Law Journal 63 (1995): 483.
} 
By contrast to traditional economic theory, behavioural economics challenges the essential tenets of rationality, stable preferences and utility maximisation. According to behavioural economics, individuals instead express bounded rationality, bounded self-control and bounded self-interest. ${ }^{9}$ Thus, making predictions about human behaviour requires the consideration of a number of biases (normally found and established through field studies $)^{10}$ that will impact rationality, preferences and utility maximisation.

Under this framework, consumer inertia is caused by bounded rationality. Consumer inertia may be caused by the bias that human beings care more about losses than about gains (loss aversion). This has been referred to as the so-called endowment effect. ${ }^{11}$ With endowment effect it is meant that human beings would ask for more to sell an endowment than they would be willing to pay for it to acquire it. ${ }^{12}$ For that reason, consumers tend to stick to the status quo as a change may mean that they will end up in a situation worse-off. ${ }^{13}$ Thus, even when there are offers that are better for consumers, they may still not be liable to switch suppliers. ${ }^{14}$ Moreover, consumer inertia may also be caused by the fact that human beings shy away from making choices in the case of too many (choice overload) or complex alternatives. ${ }^{15}$ Finally, the status quo bias may also be caused by prior commitments in terms of sunk costs. Having once committed, an individual may want to avoid regretting their prior decision, which promotes the status quo. ${ }^{16}$ All in all, the consequence of consumer inertia is that consumers may avoid to make choices or to switch suppliers even

\footnotetext{
${ }^{9}$ Amanda P. Reeves and Maurice E. Stucke, "Behavioral antitrust", Indiana Law Journal 86, no. 4 (2011): 1532.

${ }^{10}$ Andreas Heinemann, "Behavioral antitrust - A more realistic approach to antitrust", in European Perspectives on Behavioural Law and Economics, ed. Klaus Mathis (Springer, 2015), 214.

${ }^{11}$ William E. Kovacic and James C. Cooper, "Behavioral economics and its meaning for antitrust agency decision making”, Journal of Law, Economics and Policy 8 (2012): 787.

${ }^{12}$ Maurice Stucke, "Behavioral economists at the gate: Antitrust in the twenty-first century", Loyola University Chicago Law Journal 38 (2007): 513-591; Daniel Kahneman, Jack L. Knetsch and Richard H. Thaler, "Experimental tests of the endowment effect and the Coase theorem", Journal of Political Economy 98, no. 6 (1990): 1325-1348.

${ }^{13}$ Kovacic and Coooper, "Behavioral economics", 787.

${ }^{14}$ Mike Walker, "Behavioral economics: The lessons for regulators", European Competition Law Journal 13 (2017): 6; Heinemann, "Behavioral antitrust", 215-216.

${ }^{15}$ Walker, "Behavioral economics", 6; William Samuelson and Richard Zeckhauser, "Status quo bias in decision making", Journal of Risk and Uncertainty 1 (1988): 36-37.

${ }^{16}$ Samuelson and Zeckhauser, "Status quo bias", 37-38.
} 
when there is formally competition in the market. Thus, suppliers with a large installed base may be protected from actual competition and/or incumbents may be protected from potential competition. Consequently, it also opens up for suppliers to rely on consumer inertia by positioning themselves as the "default option" or making choices complex, thereby limiting competition. ${ }^{17}$

Arguably, there is a problem with the behavioural approach to consumer inertia from a practical perspective. The literature on consumer inertia, while basing itself on empirical studies that demonstrate the existence of such bias, does not seem to explain sufficiently what would affect the presence and differences in the degree of inertia. This is crucial for the application of consumer inertia as a factor in antitrust cases. As the literature points out, the same factor that may lead to consumer inertia in some cases will yield positive effects for consumers in other cases. For instance, few scholars would argue that the multitude of choices in larger supermarkets could cause harm to consumers by choice overload. ${ }^{18}$ In fact, consumers seem to prefer such supermarkets because of the availability of several alternatives. By contrast, when employees have the option on how to allocate their savings for retirement between different equity funds choice overload may become a problem. ${ }^{19}$ Obviously, the acceptance of consumer inertia as a theory cannot mean that such a bias is always present irrespective of the characteristic of the market or consumer group in the specific case. Otherwise, one assumption, that consumers are fully rational, would be substituted by another assumption, that consumers always have the tendency to stick to the status quo. From a competition law perspective, the latter assumption seems equally problematic to the traditional starting point and is likely to lead to erroneous results.

Irrespective of whether a more traditional cost-oriented approach or a behavioural approach is accepted, perhaps the more interesting issue concerns how to establish the presence of consumer inertia as a practical matter in real cases. Arguably, a more traditional cost-oriented approach may be easier to apply in the form of a theoretical argument. The establishing of

\footnotetext{
${ }^{17}$ Walker, "Behavioral economics", 7.

${ }^{18}$ Judith Metha (ed.), "Behavioral economics in competition and consumer policy", Centre for competition policy, University of East Anglia, accessed 8 March, 2018: 46. http://competitionpolicy.ac.uk/documents/8158338/8193541/CCP+economics+book+Final+digital+version+-+colour. pdf/30214557-cace-4b0b-8aac-a801bbde87bc.

${ }^{19}$ Mehta, "Behavioral economics", 47.
} 
particular costs, e.g. transition costs or information costs caused by transparency issues or uncertainty in relation to the specific consumer group in a particular case could possibly be carried out without the backing up of those claims with empirical evidence of consumer/customer behavioural patterns..$^{20}$ For instance, as regards the issue of information costs in relation to lock-in effects in aftermarkets, factors such as the nature or the value of the product, as well as the identity of the consumer are likely to have an impact on the viability of the argument of lock-in effects. ${ }^{21}$ For the reasons mentioned above, a behavioural approach could be seen as more speculative. Even though the finding of different biases is backed up by empirical studies, it does not mean that such biases are applicable in the specific market(s) in a given case. For instance, while a competition authority may show that consumers are required to engage in complex calculations in a specific market, it may be too speculative to claim that they will result in the use of (erroneous) rules of thumb or inertia by consumers if the bias cannot be connected to the (cognitive) characteristics of the particular consumer group. In addition, different groups of consumers within the same market may also differ as to the extent to which they are subject to consumer inertia. In theory, the group of rational consumers may be sufficiently large as to eliminate potential negative effects of consumer inertia by disciplining the behaviour of suppliers. Thus, an antitrust assessment would also have to consider the share of consumers that may be subject to inertia and its impact on the market. Naturally, as follows from the few cases discussed below, the behavioural approach may be successful if used as an explanation for already established consumer patterns through empirical evidence, such as customer surveys. However, when such empirical evidence is not available in a specific case, the use of consumer inertia has to rely on theoretical arguments. Accordingly, there is a need to discuss in more depth what specific factors may affect the cognitive capacity of consumer groups resulting in consumer inertia. This is particularly important in enforcement that relies heavily on a prospective analysis such as merger cases, where customer surveys may not exist at

\footnotetext{
${ }^{20}$ See e.g. the discussion on transition costs as a rationality-based explanation for the status quo bias in Samuelson and Zeckhauser, "Status quo bias", 33-35.

${ }^{21}$ See e.g. the discussion in Judgment of the General Court (Fourth Chamber) of 15 December 2010, Confédération européenne des associations d'horlogers-réparateurs (CEAHR) v. European Commission, Case T-427/08, EU:T:2010:517, paragraph 106, and Eastman Kodak Company v. Image Technical Services, 112 S. Ct. 2072 (1992): 2085-2088.
} 
the time of the competition authority's decision. This assertion should not be seen as an essential criticism of the behavioural approach to consumer inertia, but rather as a claim that the discussion in current antitrust legal writing on consumer inertia is somewhat undeveloped.

\section{Consumer inertia and the new economy}

Although consumer inertia is not by necessity related to the new economy, it is noteworthy that some of the current and most interesting antitrust cases on consumer inertia address sectors that belong to the new economy. ${ }^{22}$ A great deal has been written about the new economy and its distinct characteristics that are interesting from an antitrust law perspective. ${ }^{23}$ Features of the new economy, in particular, have raised issues regarding the accuracy of the definition of relevant markets, ${ }^{24}$ the handling of interconnection between different markets, in certain multi-sided markets, ${ }^{25}$ the sharing economy, ${ }^{26}$ the importance of network effects, ${ }^{27}$ the importance that products and services are free of charge, ${ }^{28}$ the importance of data, ${ }^{29}$ the high rate of innovation, ${ }^{30}$ as well as the assessment of anti-competitive effects in markets characterised by one or several of the features enumerated above, especially when they result in competition for markets instead of within markets. Accordingly, this section addresses consumer inertia in the context of the new economy.

In the context of the new economy, it seems that consumer inertia becomes particularly relevant in relation to multi-sided markets and

\footnotetext{
${ }^{22}$ See e.g. the discussion below in section 5 on Commission Decision, AT.39740 Google Search (Shopping), C (2017) 4444 final (Google Shopping) and Commission Decision of 6 December 2016 (M.8124 - Microsoft/LinkedIn).

${ }^{23}$ The main features of the new economy where already presented in e.g. Richard Posner, "Antitrust in the new economy", Antitrust Law Journal 68 (2001): 925-943.

${ }^{24}$ Antonio Robles Martín-Laborda, "Merger control and online platforms: The relevance of network effects", Market and Competition Law Review 1 (2017): 74-78; Joyce Verhaert, "The challenges involved with the application of Article 102 TFEU to the new economy: a case study of Google", European Competition Law Review 35 (2014): 267.

${ }^{25}$ Mäihäniemi, "The role of innovation", 114; Verhaert, "Challenges", 267; Martín-Laborda, "Mergel control".

${ }^{26}$ See e.g. Vassili Hatzopoulos and Sofia Roma, "Caring for sharing? The collaborative economy under EU law”, Common Market Law Review 54 (2017):109-112.

${ }^{27}$ Posner, "Antitrust in the new economy", 930; Verhaert, "Challenges", 267.

${ }^{28}$ Maurice E. Stucke and Allen P. Grunes, Big Data and Competition Policy (Oxford: Oxford University Press, 2016), Chapter 7.

${ }^{29}$ See e.g. Stucke and Grunes, "Big data", Chapter 4.

${ }^{30}$ Verhaert, "Challenges", 266.
} 
thereby indirect network effects. Multi-sided markets are characterised by the fact that the offering of products or services (on a specific market) is interlinked and interdependent with the offering of another product or service (which would constitute a different but interconnected market). ${ }^{31}$ The success in the offering of e.g. an operating system (OS) is dependent on the amount of applications designed for the particular OS. Thus, the more customers use the particular OS, the more attractive it becomes to develop applications for it. In other words, it becomes easier for the supplier of the OS to "sell" access to application developers. Similarly, the more a credit card provider can convince merchants to accept a card, the more attractive it becomes for potential card users to acquire the credit card. Accordingly, the two groups of customers, the users of the credit cards and the merchants using the credit card network are dependent on each other and the intermediary, the credit card network, works as the vehicle for transactions between the two groups. ${ }^{32}$ The consequence of markets being interconnected in this fashion is that occurrences in one market also have repercussions on the interconnected market. For instance, a price increase in one of the interconnected markets which decreases demand may also decrease interest for suppliers of products in the interconnected market. ${ }^{33}$ Thus, both market definition and analysis of anti-competitive effects cannot be carried out only focusing on one of the interconnected markets but require the assessment of potential effects in other interconnected markets. In addition, companies may consciously take into account the effects across the different interconnected markets when adopting a particular behaviour.

Moreover, the fact that markets are multi-sided also means that the provision of services and products is subject to network effects. Network effects are categorised, according to the literature, into direct and indirect network effects. ${ }^{34}$ With direct network effects it is meant that customers would have an increased utility, the higher the amount of other customers (within the same market) using the product or service in question. For

\footnotetext{
${ }^{31}$ See e.g. Jean-Charles Rochet and Jean Tirole, "Platform competition in two-sided markets", Journal of the European Economic Association 1 (2003): 990-1029.

${ }^{32}$ OECD Roundtable on two sided markets (2009), accessed 10 March, 2018: 11. https://www.oecd. org/daf/competition/44445730.pdf.

${ }^{33}$ Daniel Mandrescu, "Applying EU Competition Law to online platforms: the road ahead - Part 1", European Competition Law Review 38 (2017): 355; OECD Roundtable on two sided markets, 11. ${ }^{34}$ Daniel Mandrescu, "Applying EU Competition Law to online platforms: the road ahead Part 1", European Competition Law Review 38 (2017): 355.
} 
instance, the more users of a particular OS, the higher the utility for each individual user as they can share files with other users. By contrast, with indirect network effects it is meant that users of a certain product gain a higher utility, the more products or services are provided by suppliers (in the interconnected market) based on the product in question and vice versa. As explained above, developers of applications for a particular OS get a higher utility, the larger the installed base of the OS in question. While the presence of direct network effects is prominent in many markets, indirect network effects are directly relevant to multi-sided markets. ${ }^{35}$ Thus, indirect network effects may gravitate users in the different interconnected markets to a particular product to such an extent that it becomes difficult for rivals to challenge a product that has a critical mass of users/suppliers (in all of the affected interconnected markets).

In the context described above, it appears as consumer inertia may become relevant in two ways. Firstly, consumer inertia may be a factor that contributes to a position of market power by limiting competition between suppliers. However, it seems as consumer inertia must be combined with other (probably more) important factors, such as network effects and other entry barriers that lead to a situation of market power. While consumer inertia is a factor that results in the status quo, e.g. by dis-incentivising consumers to make a choice other than the default option, other factors affect the choice of the default option. Both direct and indirect network effects may "tip" the market to choose a specific product or service as a default option, e.g. by incentivising a supplier to choose a "must-have" product or incentivising suppliers of products in the interconnected markets to choose a particular platform or system. Overcoming direct network effects requires a rival to catch up by reaching a critical mass of users to challenge the dominant supplier. Additionally, overcoming indirect network effects in multi-sided markets requires the reaching of a critical mass also in the interconnected markets. Obviously, indirect network effects make it very hard for rivals by increasing the costs of both entry and expansion.

Secondly, consumer inertia may provide a mechanism for suppliers to leverage their market power in between the different interconnected markets. Suppliers may actively position themselves as the default option either through contracts or technical means, such as the technical integration of two products. Thus, even though suppliers do not "create" consumer

\footnotetext{
${ }^{35}$ OECD Roundtable on two sided markets, 11.
} 
inertia, they take advantage of this cognitive bias in the consumer group and thus raise costs for rivals, which have to overcome consumer inertia.

Outside the context of multi-sided markets, consumer inertia may also become relevant when supply of services is formally free of charge but requires or permits the collection of users' personal data. Market power may be seen as the ability to charge supra-competitive prices profitably for a longer period of time. ${ }^{36}$ Assessing whether a supra-competitive price has been charged presumes that consumers actually perceive the price for the supplied product or service as a supra-competitive price. However, the supply of services such as general internet searches or social platforms is commonly free of charge. Instead, the provider of these services will normally impose conditions for use whereby consumers agree to submit personal data. It seems as most consumers would not make an actual evaluation of such conditions. ${ }^{37}$ It seems arguable that such consumer behaviour could be attributed to consumer inertia as, for most consumers, scrutinising conditions of use is simply a task that is too complex. Probably, for most consumers agreeing to conditions which result in the transferring of personal data is not even seen as a "cost", which underlines that consumers in real markets may not engage in an in-depth cost and benefit analysis. The result of this consumer behaviour is that consumers may be more easily "exploited" through the imposition of unfair conditions or supra-competitive charges in the antitrust sense without being aware of it.

\section{The use of consumer inertia in antitrust law}

It follows from the description of consumer inertia above that it has the particular effect of a switching cost impeding the shift from the consumption of one product or service to competing products or services. Arguably, consumer inertia may be relevant in the application of antitrust rules in three different situations. Firstly, it may constitute a factor that contributes to a position of market power, in particular a dominant position in the context of applying Article 102 TFEU or the Merger Regulation. ${ }^{38}$ Secondly, consumer inertia may also be relevant for the establishment of anti-competitive behaviour either in the form of abuse under Article 102 TFEU or

\footnotetext{
${ }^{36}$ Robert Landes and Richard Posner, "Market power in antitrust cases", Harvard Law Review 94 (1981): 937-996.

${ }^{37}$ Stucke and Grunes, "Big data", 120-121.

${ }^{38}$ Council Regulation (EC) No. 139/2004 of 20 January 2004 on the control of concentrations between undertakings, OJ [2004] L 24/1 (Merger Regulation).
} 
as part of the prospective effects, constituting a significant impediment to effective competition under the substantial test in the Merger Regulation. ${ }^{39}$ Moreover, it has also been claimed that inertia may also be used to impede cheating in cartel arrangements. ${ }^{40}$ However, considering the type of cases discussed below (section 5), this particular situation will not be addressed further.

As regards consumer inertia as an element that creates or supports a position of market power, it has been discussed above that consumer inertia leads to less switching between products or services. The effects of consumer inertia may also be accentuated by other mechanisms common in the new economy, like the indirect network effects in multi-sided markets. As a consequence, competing suppliers would probably have to overcome such effects by investing in more marketing towards consumers, by concluding costly contracts to outrival the positioning of the strong incumbent supplier, or by entering several markets in order to take advantage of consumer inertia for their own supplies. Accordingly, consumer inertia may have the same effect as a barrier to entry or expansion, or as a supporting factor resulting in such barriers, leading to less competitive pressure from actual and potential competitors.

The second possibility for consumer inertia to come into the antitrust analysis is as a mechanism used as part of an exclusionary strategy. The obvious example is tying, which may be assessed both under Article 102 TFEU and the Merger Regulation. ${ }^{41}$ The demonstration of tying as an abuse requires showing that the products belong to two separate markets, that the customer is coerced to acquire the tied product (coercion), that competition is eliminated, and that there is no objective justification. ${ }^{42}$ It must be noted that the border line between coercion and the elimination of competition in tying/bundling cases is not clear-cut. Coercion is the element that may result in the elimination of competition by discouraging

\footnotetext{
${ }^{39}$ Merger Regulation, Article 2(3).

${ }^{40}$ Iwan Bos, Ronald Peeters and Erik Pot, "Competition versus collusion: The impact of consumer inertia”, International Journal of Economic Theory 13 (2017): 387.

${ }^{41}$ This is relevant for the assessment of conglomerate mergers. Guidelines on the assessment of non-horizontal mergers under the Council Regulation on the control of concentrations between undertakings, [2008] OJ C 265/6, paragraph 93; Judgment of the Court of First Instance (First Chamber) of 25 October 2002, Tetra Laval BV v. Commission of the European Communities, Case T-5/02, EU:T:2002:264.

${ }^{42}$ Judgment of the Court of First Instance (Grand Chamber) of 17 September 2007, Microsoft Corp. v. Commission of the European Communities, Case T-201/04, EU:T:2007:289, paragraphs 850-870.
} 
the substitution of the tied product. Coercion is thus the first of two tests required to demonstrate anti-competitive effects in an individual case. While it is not possible to show anti-competitive effects without coercion, it could still be the case that a dominant supplier has engaged in coercion but no elimination of competition has actually occurred. The tying/bundling measure may still not effectively prevent the substitution of the tied product, and suppliers of alternative products may still apply counterstrategies to protect or increase market shares.

Consumer inertia may be used to support a tying or bundling measure which does not constitute an outright contractual tying but still results in coercion. ${ }^{43}$ While traditional situations of tying and bundling typically result in added costs for those customers that want to circumvent the tying measure, the same does not necessarily apply to markets in the new economy where products are technically integrated (technical bundling). As explained above, one of the features of the new economy is the fact that many services offered through the internet to consumers are "free of charge". In addition, the distribution of products or services may be perceived as being costless and relatively easy. The issue of additional costs is important in the antitrust assessment of tying. It is normally the additional costs that constitute the impediment for the customer to switch to rival suppliers. Two products offered together at a lower price than when sold separately provides a direct economic incentive to purchase the bundle. Similarly, contractual tying results in added costs for customers that nonetheless would prefer purchasing competing substitutable products. Accordingly, when a tied product is available free of charge, customers are not necessarily impeded from using alternative products to the tied product. Moreover, if the coercive measure is directed towards an intermediary, like a reseller, availability of substitutes free of charge for end-consumers may still open up the market for rivals to the dominant supplier.

It is in this context that consumer inertia may be a relevant factor which results in a coercive effect or in the elimination of competition. If customers (like resellers) or end-consumers are subject to consumer inertia, this mechanism will impede switching irrespective of there being no actual costs for acquiring the substitutable product. Thus, consumer inertia may contribute to the coercive effect of technical bundling and/or impede switching to rival products, resulting in the elimination of competition.

${ }^{43}$ Heinemann, “Behavioral antitrust", 234. 
Another abuse in which consumer inertia may be relevant is refusal to supply. According to the case law, three conditions must be met for establishing the abuse: indispensability of access to the infrastructure or the input product; elimination of competition in a neighbouring market caused by the refusal to supply; and no objective justification for the refusal to supply. ${ }^{44}$ In addition, as regards refusal to license intellectual property rights, it is additionally required that the refusal hinders the emergence of a new product. ${ }^{45}$ Arguably, consumer inertia may become relevant as concerns both the requirements of indispensability as well as the elimination of competition. A dominant supplier of e.g. a platform or a software program may take advantage of consumer inertia to boost its sales of additional products or services. The existence of multi-sided markets is likely to create situations where the possibility to enter into one market is dependent on the access to the other side of the market. Thus, rivals to the dominant supplier will need access to the necessary "infrastructure" or platform on one side of the market to effectively compete on the other side of it. In this context, consumer inertia results in a disadvantage if consumers tend to choose products that are directly accessible through the particular infrastructure or platform, even if there are other potential distribution channels. Accordingly, the presence of consumer inertia may be relevant for showing the indispensability of access to the infrastructure, as well as for demonstrating that alternative distribution channels are not effective, which results in the elimination of competition in the neighbouring market.

\section{The direct and indirect application of consumer inertia in antitrust cases}

The purpose of this section is to give account of those few cases where consumer inertia appears to have played a role in antitrust cases. The different subsections focus particularly on how consumer inertia is perceived and discussed by the Courts and the Commission, analysing recent antitrust

\footnotetext{
${ }^{44}$ Judgment of the Court (Sixth Chamber) of 26 November 1998, Oscar Bronner GmbH \& Co. KG v. Mediaprint Zeitungs- und Zeitschriftenverlag GmbH \& Co. KG, Mediaprint Zeitungsvertriebsgesellschaft $m b H$ \& Co. KG and Mediaprint Anzeigengesellschaft $m b H$ \& Co. KG, Case C-7/97, EU:C:1998:569, paragraph 41.

${ }^{45}$ Judgment of the Court (Fifth Chamber) of 29 April 2004, IMS Health GmbH \& Co. OHG v. NDC Health GmbH \& Co. KG., Case C-418/01, EU:C:2004:257, paragraph 52.
} 
cases concerning the new economy where consumer inertia arguably played a role.

\subsection{Microsoft Windows Media Player and Internet Explorer}

The most noteworthy case where the idea of consumer inertia may have influenced the application of antitrust rules is Microsoft, where the company had abused its dominant position by "tying" Windows Media Player (WMP) with the operating system (OS) for PCs. ${ }^{46}$ The tying abuse in Microsoft concerned the technological bundling of the operating system with the media player. Thus, the case concerned an untraditional form of tying. As explained above, tying requires some form of coercion. In previous cases, such as Tetra Pak and Hilti, customers were coerced through the contracts or conditions imposed for purchases. ${ }^{47}$ However, technological bundling differs as two products are simply integrated into one product. An additional relevant fact in the case was that rivals to Microsoft offered products competing with the tied product, media players, free of charge. Consequently, these circumstances raised two specific issues in the demonstration of tying: firstly, whether customers were coerced to buy the additional product; secondly, whether the coercion in question resulted in the exclusion of competitors.

Importantly, the General Court (then the Court of First Instance) found that the majority of sales of Windows OS occurred through the sales of the out-of-the-box PC, that is, the sales of a new computer together with the Windows OS. Thus, the main focus of the case was the licensing of the OS to the original equipment manufacturers, the OEMs, which were putting together the PCs with additional software and selling them to the public. The Court found that coercion occurred through both contractual and technological tying. ${ }^{48}$ Firstly, there was contractual tying as the licence for the OS also included a licence for the media player and licences only for the media player were not granted. Thus, while it was theoretically possible for the OEMs to purchase a licence for an additional non-Microsoft

\footnotetext{
${ }^{46}$ Judgment of the Court of First Instance (Grand Chamber) of 17 September 2007, Microsoft Corp. v. Commission of the European Communities, Case T-201/04, EU:T:2007:289.

${ }^{47}$ Commission Decision 88/138/EEC (IV/30.787 and 31.488 - Eurofix-Bauco v. Hilti) OJ [1988] L 65/19 (Hilti Decision); Commission Decision 92/163/EEC of 24 July 1991 relating to a proceeding pursuant to Article 86 of the EEC Treaty (IV/31043 - Tetra Pak II) OJ [1992] L 72/1 (Tetra Pak II Decision).

${ }^{48}$ Judgment of the Court of First Instance (Grand Chamber) of 17 September 2007, Microsoft Corp. v. Commission of the European Communities, Case T-201/04, EU:T:2007:289, paragraphs 962-965.
} 
media player, cost constraints would impede the OEMs from adding an extra media player. Secondly, there was also technological tying as it was not possible to uninstall WMP. Consequently, it was not technically possible to offer a computer which would only include a competing media player. In response, Microsoft argued that there was no coercion as the media player was included for free and that it was still possible for consumers to download and install competing media players for free. The Court dismissed the argument that the media player was provided for free as a matter of fact. Moreover, the Court found that it was not necessary to demonstrate that end-consumers had to pay a certain price for coercion to be proved as a matter of law. ${ }^{49}$ As concerns the argument on the possibility to access other competing media players, the Court made a cross-reference to its reasoning on the elimination of the competition criterion. ${ }^{50}$ In that reasoning, discussed in more detail below, the Court found that the OEMs were deterred from installing a second media player and that end-consumers had incentives to use the pre-installed media player. Although not explicitly stated by the Court, it seems as it did not find the argument particularly relevant for the discussion on coercion. Rather, the Court seems to have established coercion through the contractual and technical tying described above. For the few sales that occurred by end-users purchasing a Windows OS separately from a computer and directly from a retailer, the licensing conditions, which were identical to those applied to OEMs, lead to the same outcome.

As regards the elimination of the competition criterion, the Commission relied on a number of arguments which were reaffirmed by the Court. It was argued, inter alia, that the technological bundling constituted a more efficient method of distribution, that the pre-installation of competing media players resulted in added costs for OEMs which therefore were given a disincentive for such a pre-installation, and that the omnipresence of WMP led to network effects inducing content providers to develop content for WMP. ${ }^{51}$ As part of the argument demonstrating the advantage of technological bundling as a distribution form, the Court addressed

\footnotetext{
${ }^{49}$ Judgment of the Court of First Instance (Grand Chamber) of 17 September 2007, Microsoft Corp.

v. Commission of the European Communities, Case T-201/04, EU:T:2007:289, paragraph 969.

${ }^{50}$ Judgment of the Court of First Instance (Grand Chamber) of 17 September 2007, Microsoft Corp.

v. Commission of the European Communities, Case T-201/04, EU:T:2007:289, paragraph 971.

${ }^{51}$ Judgment of the Court of First Instance (Grand Chamber) of 17 September 2007, Microsoft Corp. v. Commission of the European Communities, Case T-201/04, EU:T:2007:289, paragraph 1031-1089.
} 
the issue of consumer inertia. It was held that downloading of competing media players was theoretically possible, sometimes also for free, and that the internet made such downloading inexpensive. ${ }^{52}$ Thus, the exclusionary effects of the tying measures directed at OEMs could in theory be mitigated by end-consumers downloading media players from competitors to Microsoft. However, it was also found that, at the time of the Microsoft decision, downloading was seen as complicated and that many downloading attempts failed..$^{53}$ Moreover, the Court also relied on market surveys referred to in the Commission's decision showing that most consumers found that the pre-installed product would function better than products that had been downloaded and installed by end-users. ${ }^{54}$ Thus, the Court found that "vendors must deploy major resources to 'overcome end-users' inertia and persuade them to ignore the pre-installation of [Windows Media Player]". ${ }^{55}$ Additionally, the Court also found that even if there were consumers that would engage in such downloading of competing media players, WMP would nevertheless always be present in the OS as it was not possible to uninstall it. ${ }^{56}$

It follows that the Court did consider consumer inertia in its finding of tying, but not that the inertia was necessarily caused by the reasons as explained by behavioural economics. Rather, the emphasis in the Court's reasoning seems to lie in the "costs" caused by the downloading and installation performed by the end-users, as well as by the decreased functionality of such installation. The reasoning could probably also be construed as a reluctance by end-users to engage in the downloading and installation, which could leave the end-user "worse off" as a cognitive impediment to engage in switching. Instead, the Court appears mainly to have specified the switching costs affecting end-users' decision. The underlying reasons for the consumer inertia in the case seem to correspond with the view of the end-user acting as an economic rational consumer. It appears as

\footnotetext{
${ }^{52}$ Judgment of the Court of First Instance (Grand Chamber) of 17 September 2007, Microsoft Corp. v. Commission of the European Communities, Case T-201/04, EU:T:2007:289, paragraph 1052.

${ }^{53}$ Judgment of the Court of First Instance (Grand Chamber) of 17 September 2007, Microsoft Corp. v. Commission of the European Communities, Case T-201/04, EU:T:2007:289, paragraph 1050.

${ }^{54}$ Judgment of the Court of First Instance (Grand Chamber) of 17 September 2007, Microsoft Corp. v. Commission of the European Communities, Case T-201/04, EU:T:2007:289, paragraph 1050.

${ }^{55}$ Judgment of the Court of First Instance (Grand Chamber) of 17 September 2007, Microsoft Corp. v. Commission of the European Communities, Case T-201/04, EU:T:2007:289, paragraph 1052.

${ }^{56}$ Judgment of the Court of First Instance (Grand Chamber) of 17 September 2007, Microsoft Corp. v. Commission of the European Communities, Case T-201/04, EU:T:2007:289, paragraph 1083.
} 
the judgment can therefore not be seen as an incontestable support for a "behavioural argument". Moreover, it should be underlined that Microsoft does not support that the element of coercion may necessarily be proven solely by the presence of consumer inertia. The Court focused more on the contractual tying imposed on OEMs and the unavailability of Windows OS without WMP. Such argumentation does not differ much from the more traditional tying cases such as Hilti and Tetra Pak II.

The presence of consumer inertia in the behavioural sense was clearer in the Commission's commitment decision in Internet Explorer. ${ }^{57}$ In this case, the company had engaged in more or less the same practices as in Microsoft. The OEMs were, by contract, obliged to pre-install Internet Explorer as the default web browser. Also in this case, it was found that OEMs would not install a second web browser. Echoing the General Court's judgment in Microsoft, the Commission acknowledged that free download was an inexpensive way of distribution of competing web browsers. It also conceded that broadband access was more common at the time of the decision. However, it also found that downloading would still not be an effective way of distribution to consumers. This was caused by two factors. First, there were barriers to downloading in the form of technical skills for searching, downloading and installing. Second, there was simply inertia to engage in such activities. These arguments were backed up by a consumer survey that showed that a majority of consumers did not engage in downloading a second web browser when there was a pre-installed one. ${ }^{58}$ Arguably, the decision gives a stronger support for the behavioural argument. The Commission did not only refer to factors that could be translated into costs such as searching and performing the downloading and installation of the software, but also presented the presence of consumer inertia as a separate factor.

\subsection{Google Shopping}

In June 2017 the Commission adopted a decision in one of the cases involving Google regarding their comparative shopping services (Google Shopping). ${ }^{59}$ Comparative shopping services are internet-based platforms

\footnotetext{
${ }^{57}$ Commission Decision of 16 December 2009, Microsoft Tying COMP/C-3/39.530 (Internet Explorer).

${ }^{58}$ Internet Explorer, recitals 45-52.

${ }^{59}$ Commission Decision, AT.39740 Google Search (Shopping), C(2017) 4444 final (Google Shopping).
} 
which permit the consumer to compare prices between different suppliers of the same product or service. Performing a search on the internet through a general search engine (like Google or Bing) may generate hits on basis of comparative shopping services which link to the site providing the price comparison. The consumer may subsequently reach the site of the merchant by clicking the link in the comparative shopping service website.

The Commission found in its decision that a general search service is a different product market than comparative shopping services. ${ }^{60}$ Moreover, it concluded that Google held a dominant position in the market for general internet search services. ${ }^{61}$ As regards the abuse, the Commission found that Google had created a system where its own comparative shopping services would be promoted while competing comparative shopping services were demoted. ${ }^{62}$

Much simplified, the abusive conduct was implemented through two measures. Importantly, Google uses an algorithm (that searches through the whole internet) that ranks the different relevant web pages. Following a query, the algorithm evaluates the number and the quality of links to the particular webpage as a method of ranking the different relevant webpages. ${ }^{63}$ In addition, other algorithms are used to adjust the ranking of the relevant webpages. According to the Commission, Google had introduced an algorithm (so-called Panda) in its provision of generic search services which would "demote" the ranking of webpages, inter alia, on the grounds of lacking original content, e.g. when the content of the webpage (like a comparative shopping service site) would stem from another webpage (like the merchant offering the product and service in question). The effect of the algorithm was that comparative shopping webpages would be ranked much lower (showing further down the list of search results), thus attracting less numbers of user-clicks. While this first measure demoted competing shopping services, Google also applied a second measure to promote its own shopping services. The adjustment algorithm that demoted competing shopping services did not apply to Google's own shopping services ${ }^{64}$ Additionally, relevant hits to a query based on Google's own shopping services was also presented separately on top (and/or the middle) of the

\footnotetext{
${ }^{60}$ Google Shopping, recitals 145-270.

${ }^{61}$ Google Shopping, recitals 271-330.

${ }^{62}$ Google Shopping, recitals 341-343.

${ }^{63}$ Google Shopping, recital 16.

${ }^{64}$ Google Shopping, recitals 379-396.
} 
search result list on the first page as well as amongst the first links in the search result list. ${ }^{65}$ Thus, the system would "prioritise" Google Shopping services over competing shopping services. As a consequence, Google would leverage its market power in the market for generic search services to the market for shopping services.

Google Shopping is a "typical" case illustrative of the new economy. To begin with, it concerns a multi-sided market. While the offering of general search services constitutes one side of the market, the other side consists of offering merchants the possibility to market their products, either through a service like AdWords or comparative shopping services. The case also concerns a service, general search services, which formally seems to be "free of charge". While this is not completely accurate, as the Commission found that the users "paid" by granting data to Google, the company does not directly monetise through the "payment" of personal data by endusers, but indirectly by the use of those data at a subsequent stage by targeting the needs of the particular consumer. Additionally, Google indirectly monetises the value of its general search services through AdWords or its comparative shopping services as merchants either pay for the visibility or each click that goes to the merchant website which generates income.

An essential element in the Commission's argument was that consumers would normally only click the highest ranked results on the list, in particular those appearing on the first webpage. This finding was based specifically on a market survey referred to in the Commission's decision.

It could be discussed to what extent the situation above actually concerns consumer inertia. Arguably, the disincentive for consumers to scroll through more than the first page of search hits and to focus their attention on the first hits in the list of results may be characterised as inertia. Moreover, if this view is accepted, it could also be debated whether such inertia is caused by a rational cost-benefit analysis or by a behavioural bias. Obviously, the reviewing of search results going beyond the first page of search results would constitute a cost for consumers which may simply not render in the finding of better or sufficiently valuable results for such an in-depth review to be worth the effort. Alternatively, consumers may simply not engage in such a cost-benefit analysis before reviewing the results. Instead, consumers are "lazy" and shy away from the more complex

\footnotetext{
${ }^{65}$ Google Shopping, recitals 379-396.
} 
process of predicting the value of reviewing more results and instead perceive the first hits as the most relevant ones.

Finally, it should be noted that the Commission, similar to the Microsoft cases, primarily relied on consumer behavioural patterns established through market surveys rather than on a more general and theoretical argument based on costs or behavioural biases.

\subsection{Google Android}

The ongoing investigation of Google also concerns its practices regarding the Android system. The Commission sent a statement of objections in 2016 about tying practices regarding agreements and restrictive clauses entered into by Google with OEMs in the smartphone market. ${ }^{66}$ Android's operating system for smartphone devices is used in approximately $80 \%$ of all smartphones. ${ }^{67}$ Android is an open-source system. In theory, this means that OEMs may offer their smartphones with an Android open source version (so-called Android fork).

The agreements entered into by Google would impose an obligation on OEMs that want to include applications such as Google's YouTube and Play Store not to install an Android fork on any devices (the Anti-Fragmentation Agreements or AFAs). Moreover, Google also obliges OEMs that wish to install Play Store to install Google Search as a default search engine and OEMs that want to install Play Store and Search to install Google Chrome (Chrome) as a default web browser (the Mobile Application Distribution Agreements or MADAs). ${ }^{68}$

Although the detailed reasoning on the anticompetitive mechanisms is not described in the Commission's press release, it seems that also this case relies, partly, on consumer inertia. Importantly, for anti-competitive effects to occur as regards the provision of competing general search engines and web browsers, it is required that OEMs, as well as end-consumers, do not have an incentive to install and use competing products. Similar to both Microsoft cases, it seems that the demonstration of elimination of competition would require that end-consumers have no incentives to download and install competing products on their mobile devices. However, in parallel to the Microsoft cases, this would likely not be enough if OEMs would

\footnotetext{
${ }^{66}$ European Commission, MEMO 16/1484.

${ }^{67}$ Federico Etro and Cristina Caffarra, "On the economics of the Android case", European Competition Journal 13 (2017): 284.

${ }^{68}$ European Commission, MEMO 16/1484.
} 
have incentives to install competing products alongside Google Search and Chrome. While in Microsoft and Internet Explorer OEMs would suffer a cost disadvantage when installing rival products, the main problem in Google Android appears to be the limited space in mobile devices. Thus, consumer inertia seems merely to be a contributing factor that reinforces the contractual ties imposed on OEMs. For suppliers offering alternatives to Google Search and Chrome, the combination of contractual ties and consumer inertia creates entry barriers. Competing suppliers would either have to overcome the contractual ties by "paying off" OEMs to install their products or to invest heavily into their products to increase their installed base. In addition, the contracts targeting the use of Android forks diminish the possibility of competing suppliers to convince OEMs to use alternative products. To overcome such a barrier, alternative suppliers would also need to offer alternatives to those products that trigger the AFA, like YouTube.

In sum, the situation in Google Android does not appear to differ from the Microsoft cases. Consumer inertia does not seem to be the decisive factor that results in an anti-competitive effect. However, without consumer inertia, there would be a risk that the measures taken by Google to promote its own products and services would be unsuccessful as endconsumers could eliminate such effects by actively seeking, downloading and using competing products.

\subsection{Microsoft/LinkedIn}

At the end of 2016, the Commission took a favourable decision, after commitments, on the acquisition of LinkedIn by Microsoft. ${ }^{69}$ Similar to the previous Microsoft cases, one of the problematic issues was that the company would leverage its market power in the market for OS for PCs into neighbouring markets. In this case, the risk of leveraging of market power concerned the market for Professional Social Network (PSN) services. As commonly known, LinkedIn constitutes a platform that connects professionals, including prospective employers and employees. According to the Commission, Microsoft had the possibility of pre-installing LinkedIn through an application in Windows OS for PCs that would result in the exclusion of other PSN services that competed with LinkedIn.

\footnotetext{
${ }^{69}$ Commission Decision of 6 December 2016 (M.8124 - Microsoft/LinkedIn).
} 
Importantly, and parallel to the previous Microsoft cases, the Commission held that pre-installation could make switching more difficult due to consumer inertia. In fact, the Commission explicitly referred to the status quo bias. ${ }^{70}$ In addition, the Commission found that the signup on PCs was the most important segment for PSNs such as LinkedIn. Moreover, suppliers of competing PSNs would not have effective counterstrategies against the pre-installation of LinkedIn. Specifically, OEMs would not have incentives to pre-install alternative PSNs. ${ }^{71}$ However, the Commission finally cleared the merger after commitments made by the merging parties which e.g. permitted OEMs not to install the LinkedIn application and users to remove such application. ${ }^{72}$

It follows that the Commission followed its previous line of argumentation in Microsoft and Internet Explorer. An additional interesting aspect of the case is the fact that it concerned a prospective analysis under the Merger Regulation. By contrast to Microsoft, Internet Explorer and Google Shopping, the Commission could not rely on customer surveys presenting empirical evidence of the presence of consumer inertia in the relevant market. Instead, it seems that the Commission simply made an assumption based on its previous practice, an approach that could be viewed as problematic. As discussed under section 2, the behavioural approach to consumer inertia does not provide enforcers of antitrust law with sufficient specific factors that determine when consumer groups may be subject to inertia or the degree of such inertia. Without such guidelines, it becomes difficult to assess whether the Commission's finding was accurate, and it appears to be a pretty far-reaching claim that consumer inertia will always be present as soon as consumers are presented with a default option. In any case, it seems as Microsoft/LinkedIn, so far, gives the strongest support to the theory that the Commission has accepted the behavioural approach to consumer inertia in tying cases.

\section{Conclusions}

Consumer inertia must be seen as a concept that by now is firmly established within EU Competition Law. In the landmark Microsoft case, the General Court seems to have accepted the presence of consumer inertia as a supporting factor demonstrating that technical integration of different

\footnotetext{
${ }^{70}$ Microsoft/LinkedIn, recitals 309 and 320.

${ }^{71}$ Microsoft/LinkedIn, recital 320.

${ }^{72}$ Microsoft/LinkedIn, recitals 453-454.
} 
products could have a similar effect as outright coercion. Whether the General Court truly accepted the behavioural approach to consumer inertia could be debated. Nonetheless, the Commission has based subsequent decisions like Internet Explorer, Google Shopping and Microsoft/LinkedIn on the General Court's statement in Microsoft while shifting gradually to a behavioural approach.

A second observation that should be made, although an obvious one, is that even if the Commission and the General Court may have embraced consumer inertia as a factor that supports leveraging in tying cases, it remains to be seen whether the theory of consumer inertia will be accepted by the Court of Justice. In addition, consumer inertia has, so far, only been a relevant factor in tying/bundling situations. From the theoretical discussion above, it could be speculated whether consumer inertia may also be relevant in cases regarding refusal to supply.

A third interesting observation is the fact that consumer inertia has emerged as a relevant factor in cases regarding the new economy. As stated above, consumer inertia, as such, is not particular to markets in the new economy. Nonetheless, two typical features of the new economy seem to make consumer inertia a more important factor in antitrust cases. Firstly, the presence of multi-sided markets in the new economy opens up for consumer inertia to have an impact on the possibility for firms to leverage market power across markets. Secondly, it seems that many of these markets concern a more direct relation between suppliers and end-consumers, which is illustrated by cases on web browsers, search engines and media players. Thus, arguably, the behaviour of consumers has had a more direct impact in the antitrust analysis, especially in the assessment of the elimination of competition in the market. By contrast, previous and more traditional cases on e.g. tying normally concerned the relation between manufacturers and suppliers where the behavioural patterns of end-consumers were unlikely to have a decisive effect. It seems that this increased focus on actual consumer behaviour constitutes a challenge for antitrust authorities as end-consumers are perceived to be more susceptible to irrational behaviour as discussed in behavioural economics. From such a perspective, the use of consumer inertia as a behavioural bias is probably a natural response and logical development in antitrust law.

Another observation is that the Commission has so far used consumer inertia only as a supporting factor for foreclosure. In most cases, the Commission has demonstrated other factors that have prevented 
effective counterstrategies by competitors. In Microsoft, Internet Explorer, Microsoft/LinkedIn, and probably also in Google Android, the key factor has been the barrier created by e.g. the costs for OEMs to add a competing product or the limited space for pre-installing such a competing product. Consequently, competing suppliers have effectively been hindered to overcome the effects of consumer inertia. Thus, the presence of consumer inertia, as such, seems not to have triggered antitrust liability in these cases.

Moreover, it should also be noted that in almost all cases discussed above, the Commission has used the theory of consumer inertia to explain the patterns of consumer behaviour based on customer surveys. Only in Microsoft/LinkedIn was there no such empirical support for the Commission's claim. However, Microsoft/LinkedIn concerned a prospective merger analysis where such a customer survey was not available. For this reason, the case constitutes the strongest indication that the Commission has accepted a pure behavioural approach to consumer inertia and thus the inherent "irrationality" of consumers. As pointed out above, the behavioural approach in Microsoft/LinkedIn could be subject to criticism. For instance, it could be debated whether the consumers in Microsoft/LinkedIn were comparable to consumers in previous cases where the existence of consumer inertia had already been established with empirical evidence. If not, it could be questioned on basis of what evidence the Commission asserted for its finding of consumer inertia. This illustrates the current weakness with the behavioural approach to consumer inertia, as there is no clear guidance on how to establish it in real cases, apart from empirical studies.

Finally, the theory of consumer inertia gives a perfect example of how behavioural economics is gaining ground in competition law reasoning in actual cases. While such a development should be welcomed, it should not be overstated as a behavioural "revolution". The strength of behavioural theories is that they may explain, especially when backed up by empirical evidence, consumer patterns that would otherwise be inexplicable according to traditional economic theory. Thus, behavioural theories complement the toolbox based on traditional economic models that is normally applied in antitrust cases. Such a view is supported by the cases on consumer inertia, which clearly show that there was a mixture of a behavioural bias and typical entry barriers in the form of cost disadvantages and network effects that resulted in anti-competitive effects. 


\section{Bibliography}

Bos, Iwan, Ronald Peeters, and Erik Pot. "Competition versus collusion: The impact of consumer inertia”. International Journal of Economic Theory 13 (2017): 387-400.

Decker, Christopher. "Concepts of the consumer in competition, regulatory and consumer protection policies". Journal of Competition Law \& Economics 13 (2017): 151-184.

Etro, Federico and Cristina Caffarra. "On the economics of the Android case". European Competition Journal 13 (2017): 284.

Hatzopoulos, Vassili and Sofia Roma. "Caring for sharing? The collaborative economy under EU law”. Common Market Law Review 54 (2017): 109-112.

Heinemann, Andreas. "Behavioral Antitrust - A more realistic approach to antitrust". In European Perspectives on Behavioural Law and Economics, edited by Klaus Mathis, 211-242. Springer, 2015.

Kahneman, Daniel, Jack L. Knetsch and Richard H. Thaler. "Experimental tests of the endowment effect and the Coase theorem". Journal of Political Economy 98, no. 6 (1990): 1325-1348.

Klemperer, Paul. "Competition when consumers have switching costs: An overview with applications to industrial organization, macroeconomics and international trade”. Review of Economic Studies 62 (1995): 515-539.

Kovacic, William E. and James C. Cooper. "Behavioral economics and its meaning for antitrust agency decision making”. Journal of Law, Economics and Policy 8 (2012): 789-800.

Landes, Robert and Richard Posner. "Market power in antitrust cases". Harvard Law Review 94 (1981): 937-996.

Mäihäniemi, Beata. "The role of innovation in the analysis of abuse of dominance in digital markets: The analysis of chosen practices of Google Search". Market and Competition Law Review 1 (2017): 111-143.

Mandrescu, Daniel. "Applying EU competition law to online platforms: the road ahead - Part 1". European Competition Law Review 38 (2017): 353-365.

Marini-Balestra, Federico and Riccardo Tremolada. "Digital markets and merger control: balancing big data and privacy against competition law - a comment on the European Commission's Decision in the Microsoft/LinkedIn Merger”. European Competition Law Review 38, no. 7 (2017): 337-345.

Martín-Laborda, Antonio Robles. "Merger control and online platforms: The relevance of network effects". Market and Competition Law Review 1 (2017): 69-100.

Metha, Judith (ed.). "Behavioral economics in competition and consumer policy". Centre for competition policy, University of East Anglia, accessed 8 March, 2018. 
http://competitionpolicy.ac.uk/documents/8158338/8193541/CCP+economics+bo ok+Final+digital+version+-+colour.pdf/30214557-cace-4b0b-8aac-a801bbde87bc.

OECD Roundtable on two sided markets (2009), accessed 10 March, 2018: 11. https:// www.oecd.org/daf/competition/44445730.pdf.

Posner, Richard. "Antitrust in the new economy". Antitrust Law Journal 68 (2001): 925-943.

Reeves, Amanda P. and Maurice E. Stucke. "Behavioral antitrust". Indiana Law Journal 86 (2011):1527-1586.

Rochet, Jean-Charles and Jean Tirole. "Platform competition in two-sided markets". Journal of the European Economic Association 1 (2003): 990-1029.

Salop, Steven and Joseph Stiglitz. "Bargains and rip-offs: A model of monopolistically competitive price dispersion". The Review of Economic Studies 44, no. 3 (1977): 493-510.

Samuelson, William and Richard Zeckhauser. "Status quo bias in decision making". Journal of Risk and Uncertainty 1 (1988): 7-59.

Shapiro, Carl. "Making sense of Kodak". Antitrust Law Journal 63 (1995): 483.

Stucke, Maurice E. "Behavioral antitrust and monopolization”. Journal of Competition Law and Economics 8 (2012): 545.

Stucke, Maurice. "Behavioral economists at the gate: Antitrust in the twenty-first century”. Loyola University Chicago Law Journal 38 (2007): 513-591.

Stucke, Maurice E. and Allen P. Grunes. Big Data and Competition Policy. Oxford: Oxford University Press, 2016.

Verhaert, Joyce. "The challenges involved with the application of Article 102 TFEU to the new economy: a case study of Google". European Competition Law Review 35 (2014): 265-273.

Walker, Mike. "Behavioral economics: The lessons for regulators". European Competition Law Journal 13 (2017): 1-27.

Williamson, Oliver. Markets and Hierarchies: Analysis and Antitrust Implications. New York: The Free Press, 1975.

Williamson, Oliver. The Economic Institutions of Capitalism. New York: The Free Press, 1985. 